cians receive under Medicare, the impact of hospital and insurance consolidation, greater impact of poorly functioning electronic health records on solo and small independent practices, and the poor recovery of rural communities after the economic downturn.

This is not to say that inner-city underserved patients are not also in crisis, only that the health care situation in rural America is dire and has the potential to become much worse. The solutions to the rural health care crisis are also relevant to inner-city underserved patients. These populations share many problems with care access and delivery. The family physicians practicing in these locations share issues with payment, workforce, and scope of practice. Solutions for rural communities will benefit inner-city underserved communities, as well.

The AAFP task force on maternal mortality, created as directed by the 2018 Congress of Delegates, overlaps with the work of our rural initiative. The task force, which will report back to the COD in the fall, has been tasked with

- Evaluating evidence-based methods to decrease maternal mortality

- Reviewing methods to increase recognition of implicit bias and reduce disparities in maternal morbidity and mortality

- Developing strategies to help improve resident education and support practicing family physicians providing full-scope reproductive and maternity care

- Addressing the growing loss of rural maternity services nationwide

In my role as president of the AAFP and as a rural family physician who provides maternity care, I have participated in a variety of forums and venues, including national meetings of the American College of Obstetricians and Gynecologists and the National Rural Health Association as well as the National Governors Association's meeting on health care workforce development; the CMS Conversations on Maternal Care forum; the March for Moms in Washington, DC; and a hearing of the US Senate Committee on Finance.

At all these events I have been able to talk about the importance of a well-trained, comprehensive family physician workforce, and the impact this has on preventing hospital closures, as well as improving life expectancy and outcomes. I also talk about the importance of a robust loan repayment plan to encourage medical students to pursue rural family medicine as a career.

The AAFP has been developing stronger strategic relationships with NRHA, ACOG, the American Hospital Association, March for Moms, and the Rebuild Rural Infrastructure Coalition, among others. For example, we have been working with NRHA to prevent further hospital closures and reduce further obstetrical unit closures.
With regard to advocacy, we have been pushing for funding for teaching health centers, which we see as important for developing the family physician workforce the nation needs, especially in rural communities. In addition, we are advocating for removal of funding caps for hospitals that have had a previous rotating resident. We have vehemently argued that rural health care must be paid at a higher level, and that new payment models must take rural family physicians' practices into account.

As part of this initiative, the AAFP is working to ensure that rural family medicine is a part of the national dialogue. For example, the Academy has added a Rural Health Equity Fellowship to its Health Equity Fellowship program. The rural fellow will participate with the overall health equity program and in addition will have a rural curriculum, mentoring, and project relevant to rural health equity. The goal of the fellowship is to develop family physicians into leaders who have subject matter expertise in the social, institutional, and cultural influences that impact health. Fellows will become leaders who can facilitate change to improve their local communities and primary care.

Seventeen percent of our members practice in rural communities. Many provide obstetrical care and emergency medical services under some of the most challenging conditions possible. This strategic initiative has been created in recognition of the neglect rural communities have faced and the primacy of family medicine in delivering rural health care.

For those of you working in rural communities, thank you for what you do. Family physicians are the rural safety net.

Jobn Cullen, MD AAFP President

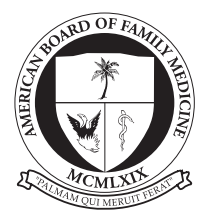

From the American

Board of Family Medicine

Ann Fam Med 2019;17:472-475. https://doi.org/10.1370/afm.2457.

\section{PURSUING PRACTICAL PROFESSIONALISM: FORM FOLLOWS FUNCTION}

Still early in a long game of delivery system transformation, the United States is already experiencing some of the negative consequences of pursuing quality and value measurement on professionalism in health care, specifically in the form of provider burnout. Other countries have struggled with similar endeav- 
ors, including the United Kingdom, which in 2004 launched an important experiment in value-base payment called the Quality and Outcomes Framework, or the QOF ("Qwaf"). The QOF increased primary care payments by up to $25 \%$ depending on how physicians did on more than 120 measures. ${ }^{1}$ The QOF was associated with improvements in several measures similar to those used currently in the United States such as smoking status, blood pressure control, and cholesterol management for patients with coronary heart disease or prior stroke. Improvement was directly aligned with incentives for when 12 measures were removed from the incentive list, there was significant erosion of previous improvement. ${ }^{2}$ The QOF was also associated with reductions in patient-centered outcomes, like continuity, and with increased physician burnout. ${ }^{3}$ In fact, one of the lessons from the QOF is that, "aligning financial incentives with professional values may reduce the risk of unintended consequences."3 Scotland abandoned the QOF in 2016 and England reduced the number of QOF measures by one-third while also substantially reducing its role in physician income. ${ }^{4}$ As the United Kingdom was backing away from its pay-forperformance scheme, the United States launched the Quality Payment Program, without attending or adapting to the valuable lessons that the United Kingdom offered. Specifically, the United States failed to align these potent drivers of behavior with clinicians' intrinsic motivations to deliver good care. Below, we review how such alignment might galvanize a new era of practical professionalism, by using policies that purposefully harness lessons from behavioral economics and principals derived from systems engineering. In doing so, we propose the creation of a built environment for health care in which delivering good, cost-effective care is not only the easy choice but one that supports professionalism and joy.

Madera and Burkhart writing in a special issue of JAMA in 2015 made the profound statement that, "Physician organizations need to use their self-regulatory influences to better craft environments that leverage these intrinsic motivators derivative of professionalism

.. The work may be difficult, but the goal is simple: by structuring practice environments with the intrinsic incentives and motivators of professionalism, have physicians help accomplish the Triple Aim by relying on the simple fact that this is actually what they want to do." Enabling physicians to accomplish the Triple Aim does not need to work contrary to their intentions; we similarly propose that designing practice environment to align with professional intentions is a strategy for turning the Triple Aim into the Quadruple Aim—adding joy in practice to the expected outcomes. Board certification provides one mechanism for the medical profession to demonstrate accountability to the social contract for health care, whereby physicians enjoy considerable privileges in exchange for careful selfregulation. The American Board of Family Medicine (ABFM) endorsed Madera and Burkhart's observation, noting that "Certifying boards have an opportunity to support physicians in improving the quality and safety of health care and appeal to physicians' intrinsic motivation for doing so...The ABFM is not retreating from that challenge but is instead listening carefully to family physicians and making strategic investments to evolve." In one such investment, the ABFM in 2018 launched the Center for Professionalism \& Value in Health Care, committing to working with others to advance alignment of how clinicians are valued (measures, payment, certification) with intrinsic motivations and behaviors critical to good care. ${ }^{7}$ This new Center will specifically apply principles of behavioral economics and systems engineering to study relationships between professionalism and value, with the intention of promoting their alignment, informing effective policy and design that support professional behavior, improve outcomes, and enhance joy in practice.

In 2013, the systems side of this equation was addressed in a joint report by the National Academy of Engineering and the Institute of Medicine (since renamed the National Academy of Medicine). That report made a profound opening statement:

"Quality and safety shortfalls occur even as clinicians expend considerable time and effort caring for their patients. The problem is not with the individuals working in the health care enterprise, but with the design and operation of the multiple systems in health care. As currently designed, these systems depend on the heroism of clinicians to ensure patient safety and promote care quality. At the same time, they add unnecessary burdens to clinical workflows, silo care activities, and divert focus from patient needs and goals." ${ }^{\prime 8}$

In the years since, we're increasingly aware that the problems described in the IOM/NAE report are a considerable source of health-professional burnout. The report proposed many systems engineering insights and solutions; however, breaking care down into component parts and parsing these to the most efficient means of delivering them risks over-engineering. This "widgetizing" of health care feeds the notion that everything that matters can and should be systematized and measured. What works in Toyota production plants may not perfectly apply to the uniquely human endeavor that is health care. The report has considerable value for its elegant summary of insights on the application of engineering principles in other business lines to reduce burden and align work with desired outcomes. The report also characterized the 
relative complexity of health care, and specifically primary care, citing a 2008 study of a large multispecialty practice in Massachusetts that found the average primary care physician managed 370 unique primary diagnoses, each associated with a set of evidence-based practices $_{i} 600$ unique medications $;$ and approximately 150 unique laboratory tests. ${ }^{9}$ The report concluded from this that, "complexity of health care extends beyond these specific examples to permeate all aspects of clinical care, and highlights the need for systems approaches to delivering care."

Among the most important insights emerging from Sinsky's and Bodenheimer's seminal studies of high-functioning primary care practices is the conclusion that most of them also experienced considerable joy. A key ingredient in achieving professional "joy" identified by both teams was the systematic redistribution of work in the practice that sought to have care team members working at the top of their abilities. Their conclusion was that this redistribution created meaningful work for most of the team while reducing burden. ${ }^{10}$ Dr Sinsky, since joining the American Medical Association (AMA) staff leadership, has focused on scaling and translating these lessons into an interactive practice transformation series and CME offering. ${ }^{11}$ It currently consists of a practice assessment tool, 54 modules, and a variety of videos and resources. Parallel but equally important are efforts to develop related policy guidance to align policy with these practice transformation principles. ${ }^{12}$ Similarly, the National Academy of Medicine and a wide range of collaborators have produced the Clinician Well-Being Knowledge Hub which includes resources and case studies demonstrating policies and system redesigns that reduce risk of burnout..$^{13}$ This alignment of structure and policy could reduce burden, reduce burnout, increase purposefulness, and positively reinforce professional behavior rather than make it the heroic response to rescuing patients when current system design fails them. The relationship between burnout and professionalism is well established and there are overlaps in the solutions, particularly regarding design, but professionalism also needs attention to alignment of how we are valued vs caring for patients. ${ }^{14}$

Health care has much to learn from behavioral economics, the convergence of economics and psychology largely pioneered by Amos Tversky and Daniel Kahneman for which the latter received the Nobel Prize. Their pioneering research, in contrast to the principles of classical economics, suggested that humans are not always rational actors; their behaviors are frequently guided by mental short cuts, unrecognized biases, and susceptibility to the way in which choices are framed. In describing its applications to public health, Matjasko and colleagues effectively summarized behavioral economics, saying it, "provides an empirically informed perspective on how individuals make decisions, including the important realization that even subtle features of the environment can have meaningful impacts on behavior." ${ }^{15}$ The related concept of "nudge" was heavily influenced by Richard Thaler (2017 Nobel Prize) and Cass Sunstein in their book by the same name as "any aspect of the choice architecture that alters people's behavior in a predictable way without forbidding any options or significantly changing their economic incentives. ${ }^{16}$ Its acceptance as a field able to influence policy is exemplified by its formal adoption by the UK government in 2010 with the creation of the Behavioral Insights Team and by the US government in 2014 with the White House Social and Behavioral Science Team. ${ }^{15}$ In the 1980s, Amos Tversky partnered with Stanford researchers on some of the earliest studies of behavioral economics in medicine. They found that physicians give more weight to patients' personal concerns when considering them as individuals and more to general care effectiveness when considering them as a group. ${ }^{17}$ They also found that the way in which treatment information is presented to patients and physicians influence their choices between alternative therapies. ${ }^{18}$ More recent studies of Accountable Care Organizations highlight the dangers of over-reliance on financial motivators for physicians, the growing evidence of the potency of nonfinancial motivators, and the need to harmonize quality measures to make them more useful for behavior change. ${ }^{19}$ Recent studies also suggest ways that financial incentives can be used to support desired behaviors and avoid unintended consequences, like those of the UK's QOF. ${ }^{20}$ But the evidence for the application of behavioral economics to frontline health care is sparse. While it deserves more research, there is considerable evidence from outside medicine to suggest that we can design incentives and settings to extrinsically nudge behavior that is aligned with intrinsic, professional behavior-to make professional behavior the default and easy choice. Bringing this focus into health care could give important balance to systems engineering and guidance to the introduction of Sinsky's practice redesign.

In 2009, Kevin Grumbach exposed us all to the guiding principle of the Bauhaus School of Crafts and Architecture, namely, that form follows function. ${ }^{21}$ Bauhaus, he points out, emphasizes rational and simplified design. Grumbach's principles for health care redesign are most powerful in their reiteration of that guiding Bauhaus principle, that form follows function. There is a real opportunity to design clinical settings, decision-support, team design, and resource flow to retain clinician autonomy while nudging behaviors in 
purposeful directions that are consistent with their professional intentions and desired health and health system outcomes. We need form that supports the professional function. There is a real need for practical applications of what is already known to help stave off an epidemic of burnout. The misalignment of current system design, incentives, and support is having devastating effects on the workforce that is already translating to patient outcomes. ${ }^{14}$ Health care professionals are increasingly employed and while some leading ACOs are doing important experimentation to support what we call practical professionalism, there is a broader need for rapid translation of learning into practice. Health care is now nearly $20 \%$ of our economy and we are experiencing unprecedented erosion of population health outcomes. ${ }^{22}$ Enabling practical professionalism is critical to the social contract and its economic and health outcomes. Practical professionalism will require support across medical specialties, from other health professionals, and by patients for health system design and related policies that enable professional behavior by design to achieve improved outcomes, costs, experience, and joy.

Robert L. Phillips, Jr, MD, MSPH, Center for Professionalism and Value in Health Care,

Andrew W. Bazemore, MD, MPH, and Warren P. Newton, MD, MPH, The American Board of Family Medicine

\section{References}

1. Campbell SM, Reeves D, Kontopantelis E, Sibbald B, Roland M. Effects of pay for performance on the quality of primary care in England. N Engl J Med. 2009;361(4):368-378.

2. Guthrie B, Roland M, Minchin M. Quality of care in the United Kingdom after removal of financial incentives. N Engl J Med. 2018; 379(22):2179.

3. Roland M, Campbell S. Successes and failures of pay for performance in the United Kingdom. N Engl J Med. 2014;370(20): 1944-1949.

4. Minchin M, Roland M, Richardson J, Rowark S, Guthrie B. Quality of care in the United Kingdom after removal of financial incentives. N Engl J Med. 2018;379(10):948-957.

5. Madara JL, Burkhart J. Professionalism, self-regulation, and motivation: how did health care get this so wrong? JAMA. 2015;313(18): 1793-1794.

6. Phillips R, Kennedy J. Jaén C, Stelter K, Puffer J. Transforming physician certification to support physician self-motivation and capacity to improve quality and safety. Journal of Enterprise Transformation. 2016;6(3-4):162-169.
7. The Center for Professionalism $\&$ Value in Health Care. www.professionalismandvalue.org. Accessed Aug 10, 2019.

8. Kaplan G, Bo-Linn G, Carayon P, et al. Bringing a Systems Approach to Health. Washington, DC: Institute of Medicine and National Academy of Engineering; 2013.

9. Semel ME, Bader AM, Marston A, Lipsitz SR, Marshall RE, Gawande $A A$. Measuring the range of services clinicians are responsible for in ambulatory practice. J Eval Clin Pract. 2012;18(2):404-408.

10. Sinsky CA, Willard-Grace $R$, Schutzbank AM, Sinsky TA, Margolius $D$, Bodenheimer $T$. In search of joy in practice: a report of 23 high-functioning primary care practices. Ann Fam Med. 2013;11(3): 272-278.

11. AMA launches STEPS Forward to address physician burnout [press release]. Chicago AMA, 2015.

12. Sinsky $C A$. Designing and regulating wisely: removing barriers to joy in practice. Ann Intern Med. 2017;166(9):677-678.

13. National Academy of Medicine. Clinician Well-Being Knowledge Hub. Washington, DC: National Academy of Sciences; 2019. https://nam. edu/clinicianwellbeing/.

14. Panagioti M, Geraghty K, Johnson J, et al. Association between physician burnout and patient safety, professionalism, and patient satisfaction: a systematic review and meta-analysis. JAMA Intern Med. 2018;178(10):1317-1330.

15. Matjasko JL, Cawley JH, Baker-Goering MM, Yokum DV. Applying behavioral economics to public health policy: illustrative examples and promising directions. Am J Prev Med. 2016;50(5)(Suppl 1): S13-S19.

16. Thaler R, Sunstein C. Nudge: Improving Decisions about Health, Wealth, and Happiness. New Haven, CT: Yale University Press; 2008.

17. Redelmeier DA, Tversky A. Discrepancy between medical decisions for individual patients and for groups. N Engl J Med. 1990;322(16): 1162-1164.

18. McNeil BJ, Pauker SG, Sox HC Jr, Tversky A. On the elicitation of preferences for alternative therapies. N Engl J Med. 1982;306(21): 1259-1262.

19. Phipps-Taylor M, Shortell SM. More than money: motivating physician behavior change in accountable care organizations. Milbank Q. 2016;94(4):832-861.

20. Lubarsky DA, French MT, Gitlow HS, Rosen LF, Ullmann SG. Why money alone can't (always) "nudge" physicians: the role of behavioral economics in the design of physician incentives. Anesthesiology. 2019;130(1):154-170.

21. Grumbach K. Redesign of the health care delivery system: a Bauhaus "form follows function" approach. JAMA. 2009;302(21): 2363-2364.

22. National Research Council, Institute of Medicine. In: Woolf S, Aron $\mathrm{L}$, eds. U.S. Health in International Perspective: Shorter Lives, Poorer Health. Washington, DC: National Academies Press, National Academy of Sciences; 2013. 